\title{
CRIAÇÃO DE VALOR EM AMBIENTE B2B: UMA REVISÃO DE MODELOS RELEVANTES ${ }^{1}$
}

\author{
CREATING VALUE IN a B2B ENVIRONMENT: A REVIEW OF RELEVANT \\ TEMPLATES
}

\author{
Irene Raguenet Troccoli ${ }^{2}$
}

RESUMO: O objetivo deste artigo é revisar modelos relevantes de prospecção da criação de valor por meio do compromisso mútuo gerado nos relacionamentos entre parceiros situados em redes de negócios no mercado business-to-business (B2B). Em outras palavras, estudar o processo de cocriação de valor entre players industriais. A metodologia utilizada é a revisão bibliográfica sistemática e crítica de modelagens relevantes voltadas para este estudo. Os resultados encontrados indicam que estes modelos têm apresentado crescente sofisticação. A conclusão é de que a pesquisa acadêmica da Administração de Empresas voltada para as redes estratégicas e de relacionamentos tem mostrado crescente interesse pelo fenômeno da criação de valor por meio da interação dos agentes atuantes no mundo dos negócios nos mercados industriais. Crescentemente, a curiosidade tem se voltado para a compreensão deste processo criatório, abandonando-se o entendimento tradicional de que o valor seria algo estático e mensurável objetivamente.

PALAVRAS-CHAVE: cocriação de valor, mercado B2B, modelos.

ABSTRACT: The purpose of this paper is to review relevant models of value co-creation concerning the mutual engagement of actors in business-to-business (B2B) markets. In other words, to study the value co-creation process between industrial players. The method used is systematic and critic bibliography review of the relevant models concerning this field of research. The results show that these models are increasingly sophisticated, curiosity being directed to the comprehension of the creation process, gradually abandoning the traditional view that value is something static and measurable. It is concluded that the academic research in Business Administration towards strategic and relationship networks has shown growing interest in the value creation phenomenon through the interaction of the agents present in industrial markets businesses.

KEY WORDS: value co-creation, B2B market, models

\footnotetext{
${ }^{1}$ Artigo Recebido em 11.05.2009. Revisado por pares em 10.11.2009. Recomendado em 05.07.2010 por Leomar dos Santos Editor. Publicado em 08.09.2010.

Organização Responsável pelo periódico: Universidade regional de Blumenau - FURB - www.furb.br/rn
}

\footnotetext{
${ }^{2}$ Universidade Estácio de Sá - UNESA - irene.troccoli@estacio.br
} 


\section{INTRODUÇÃO}

Atualmente, ainda é limitado o entendimento sobre o processo em que dois atores um comprador e um vendedor - envolvidos em um relacionamento de negócios criam valor ao longo do tempo. Pouco se sabe a respeito de quais fatores passados e presentes são cruciais para a forma como o valor é criado conjuntamente pelas partes. Além do mais, muito do que é praticado no mercado de relações empresariais ainda se baseia na teoria econômica de que é arriscado, para as empresas, cooperarem entre si, já que isto implicaria tornar-se dependente, contrariando a lógica econômica que prega a independência e a detenção de poder de barganha. Ou seja, ainda é restrito o entendimento de como a interdependência, criada ao longo de anos de interação, pode ser vista como um recurso que pode ser administrado e explorado para a cocriação de valor.

Por isto mesmo, de forma paulatina, o foco de um grande número de pesquisas se move do tradicional exame da criação do valor do cliente - isto é, de como o produtor de um bem ou serviço pode maximizar seu retorno por meio de suas relações com a clientela - para o processo por meio do qual as partes que vivem uma relação de negócios criam valor conjuntamente.

Ao se discutirem recursos heterogêneos possuídos por dois agentes em uma relação comprador-vendedor, a questão da interação torna-se crucial. Isto porque as partes interagem para tirar, cada uma, o melhor proveito de seus próprios recursos, dos recursos da outra parte, e dos recursos em conjunto. Vai daí que o sucesso ou o resultado da relação é altamente dependente de quão bem cada agente use os recursos dominados pelo outro agente.

Esta interação, portanto, é influenciada pelas partes envolvidas e pelo contexto em que elas se envolvem. Assim, é a história do relacionamento que moldará esta interação em seus aspectos presente e futuro, ao mesmo tempo em que o momento presente molda a forma de interpretar-se a história do relacionamento. Afinal, a interação é um processo, estando em movimento constante e sujeita a mudanças freqüentes.

O problema da incompreensão da dinâmica da cocriação de valor em relacionamentos comprador-vendedor atinge fundamentalmente os executivos envolvidos em relacionamentos de negócios. Quando estes não conseguem ver o valor de um relacionamento no mundo atual, complexo e dinâmico, isto implica a perda de oportunidades de negócios. Assim, a escolha pelo engajamento em uma parceria de alto envolvimento em substituição a uma abordagem meramente transacional com um fornecedor ou um cliente é uma escolha estratégica.

Por isto, os benefícios da cooperação estão sendo cada vez mais reconhecidos em mercados industriais. Contudo, cooperar significa praticar estratégia intensiva em recursos. Ademais, ver a cooperação como benéfica per se é simplificar demais o assunto: a escolha pela estratégia cooperativa ao invés de uma prática meramente transacional deve ser vista como uma escolha estratégica que merece muita atenção.

Assim, a definição da cocriação de valor tem sido revisitada, à luz da configuração atual do mundo caracterizado pelos relacionamentos e redes, no qual a interdependência pode ser vista como uma força positiva.

Mesmo assim, alguns problemas se colocam para os executivos que têm que entender e lidar com esta nova realidade. Um deles é que os critérios de seleção que usam quando categorizam os relacionamentos e quando desenvolvem estratégias de administração de relacionamentos, frequentemente não são ricos o suficiente para garantir um bom entendimento de como devem ser alocados os recursos para a administração de diferentes relacionamentos. Isto porque estes critérios são geralmente baseados em valores oriundos do relacionamento que sejam diretamente quantificáveis. Ou seja, os executivos não conseguem ver as fontes indiretas de valor que podem surgir de um relacionamento. 
Outro problema é a crença tradicional do homo economicus de que o que importa é a maximização do lucro por meio de comportamento oportunista. Esta tradição impede a adoção de uma nova lógica nos negócios, de uma nova forma de pensar sobre o que seja lucrativo para a empresa. Ter a capacidade de ver a interdependência como chave para uma nova lógica em parcerias comprador-vendedor é um desafio, pois requer mudanças em conceitos arraigados a respeito da administração dos negócios.

Assim, este artigo revisita a criação de valor por meio do compromisso mútuo gerado nos relacionamentos entre parceiros situados em redes de negócios no mercado business-tobusiness. Em outras palavras, estuda o processo de cocriação de valor entre players industriais. Afinal, hoje não mais é suficiente apenas saber o que a outra parte deseja para garantir-lhe a satisfação do negócio efetuado e a perpetuação deste. Não mais basta propor um produto ou um serviço que atenda às necessidades percebidas dos clientes, preferencialmente adequado ao poder de compra deste, e com preço afinado com o custo de produção.

Mais do que isto, é necessário que ambos os lados entendam o universo que os cerca em aspectos que transcendem seu próprio mundo corporativo. Afinal, cada vez mais eles encontram-se envolvidos em uma rede de elementos sociais, psicológicos, ambientais, políticos e tecnológicos que, simultaneamente, interagem para definir sua decisão de consumo.

Em que pesem estes argumentos, atualmente ainda é limitado o entendimento sobre o processo em que dois atores - um comprador e um vendedor - envolvidos em um relacionamento de negócios criam valor ao longo do tempo. Pouco se sabe a respeito de quais fatores passados e presentes são cruciais para a forma como o valor é criado conjuntamente pelas partes. Além do mais, muito do que é praticado no mercado de relações empresariais ainda se baseia na teoria econômica de que é arriscado, para as empresas, cooperarem entre si: isto implicaria tornar-se dependente, contrariando a lógica econômica que prega a independência e a detenção de poder de barganha. Ou seja, ainda é restrito o entendimento de como a interdependência, criada ao longo de anos de interação, pode ser vista como um recurso que pode ser administrado e explorado para a cocriação de valor.

Além disto, em qualquer ambiente onde as empresas busquem estreitar seus relacionamentos com parceiros industriais, a coordenação interfirmas deve ser eficiente e eficaz. A coordenação relacional requer, dentre outros, a habilidade para determinar os custos, os benefícios e os investimentos associados com o próprio relacionamento, além de uma compreensão muito clara do papel estratégico em termos de resultados sociais e econômicos que compõem o valor do relacionamento.

Explorando a natureza dos mecanismos de coordenação relacional que emergem dos interesses coletivos das empresas em relacionamentos diádicos - ou seja, pertinentes a dois players - este artigo lança mão de modelos considerados relevantes porquanto examinam a importância de construtos relacionais chave para a explicação do valor do relacionamento que é criado entre parceiros em uma cadeia de valor no mercado business-to-business (B2B).

Questionando a visão dual de que uma transação entre dois parceiros industriais implica a venda e a aquisição ou de bens físicos ou de serviços - com pequena exceção àqueles bens que tradicionalmente trazem consigo um serviço - este artigo possui dois propósitos: 1) enfocar a lógica serviço-dominante como contestatória a esta separação entre bens e serviços, examinando sua colaboração à construção da teoria da cocriação de valor; e 2) introduzir o caso da citricultura brasileira, onde o relacionamento dos dois principais players - citricultores e indústria de suco - apresenta-se como interessante ao estudo de oportunidades de cocriação de valor que se perdem por uma questão de incapacidade de alinhamento dos interesses de ambas as partes, em que pese a dependência mútua que 
apresentam. Este segundo ponto pretende ser um primeiro passo para uma futura colaboração acadêmica à Agenda $2015^{3}$, na qual se examinariam os mecanismos de coordenação relacional que emergem dos interesses coletivos tanto da indústria de suco quanto dos citricultores a partir da interação empresarial pertinente à cocriação de valor em ambiente B2B.

O enfoque aqui se dá via a análise de modelagens que possibilitem o melhor entendimento deste novo paradigma, apoiadas em metodologias fundamentalmente qualitativas, com apoio eventual de ferramentas quantitativas. Lançando mão destes instrumentos, especificamente volta-se à avaliação da cocriação de valor no ambiente empresarial encontrado no ramo do agronegócio voltado para a produção de laranja e do seu suco, especificamente no que tange à rede de relacionamentos praticada pelos produtores independentes da fruta e pelas empresas adquirentes desta para sua transformação em suco.

No meio acadêmico da Estratégia Empresarial e do Marketing, vem-se observando aumento do interesse pelos estudos voltados para a cocriação de valor entre parceiros de negócios e para o marketing de relacionamento executado entre estes mesmos parceiros. Contudo, a crescente riqueza de especificidades e de nuances do mundo atual têm imposto, ao decisor empresarial, uma velocidade de apreensão e de entendimento destes elementos que nem sempre se revela possível.

Assim, às tradicionais necessidades econômicas impostas e aos atrativos funcionais exigidos pelos clientes, outros elementos passaram a ser igualmente importantes na busca pela construção de relacionamentos com parceiros industriais. Academicamente, isto implica a necessidade de uma constante revisita às estratégias de relacionamento entre estes parceiros, de forma que sua compreensão à luz destes novos elementos possa garantir a necessária cocriação de valor.

\section{$\underline{\text { Referencial téorico }}$}

\section{A lógica serviço-dominante}

Dito de uma forma muito simples e resumida, a lógica serviço-dominante entende que, por trás de todo e qualquer bem físico, existe a prestação de um serviço relacionado, e que é isto que dá o real valor àquele bem físico. Assim, no caso de uma motocicleta, mais do que um aglomerado de peças interligadas e pousadas sobre duas rodas, ela provê, ao seu usuário, vários benefícios - transporte barato e rápido, efeito-demonstração - que são o que realmente importa para quem o adquiriu.

No meio acadêmico, esta lógica foi examinada por vários autores, dentre eles destacando-se Vargo e Lusch (2004). Estes lançaram-lhe oito premissas embasadoras, que, antes de se apresentarem como "regras", visam a criar um melhor entendimento quanto aos construtos de valor e de troca ali aplicados.

$1^{\text {a }}$. A aplicação de habilidades e de conhecimento especializados é a unidade de troca fundamental: conforme dito anteriormente, a aquisição de um bem ou de um serviço deve ser vista além de uma troca em termos simples, constituindo uma “aquisição de valor” .

\footnotetext{
${ }^{3}$ Documento diagnóstico dos segmentos citrícolas mundial e brasileiro lançado em fins de 2006 por grupo de pesquisadores da Universidade de São Paulo - USP, agregado no seu Programa de Agronegócios - Pensa, com vistas a indicar uma agenda de trabalho para o setor citrícola para a década seguinte, em termos de ações privadas e públicas nos seus diferentes segmentos - insumos, produção, indústria processadora, logística e consumo - para que esta cadeia produtiva amplie sua liderança e dominação global por meio de sua competitividade.
} 
$2^{\mathrm{a}}$. A troca indireta mascara a unidade fundamental de troca: a divisão do trabalho e a consequente especialização dos trabalhadores afastaram estes últimos da interface com os clientes tanto finais como internos à organização, assim como as organizações também se especializaram e se afastaram desta interface (por exemplo, apenas produzindo, passando a distribuição a terceiros). Isto mascarou a natureza das trocas, e contribuiu para que a qualidade passasse a ser um conceito cada vez mais distante, ignorando-se os clientes internos e externos, e dando margem ao aparecimento de várias técnicas administrativas que buscassem restabelecer o foco organizacional e dos trabalhadores na qualidade e naqueles clientes (por exemplo, a Gestão pela Qualidade Total).

$3^{\text {a }}$. Os bens são os mecanismos de distribuição dos serviços oferecidos: esta premissa se encaixa no princípio de que os produtos tangíveis são o encapsulamento do conhecimento ou das atividades, sob a forma de matéria, em seguida tornando-se o canal de distribuição para a aplicação de habilidades (ou seja, de serviços).

$4^{\mathrm{a}}$. O conhecimento é fonte fundamental de vantagem competitiva: para Vargo e Lusch, o conhecimento é fundamental para a vantagem competitiva e para o crescimento econômico. De acordo com Quinn, Doorley e Paquette (1990), “....recursos físicos, incluindo um produto claramente superior, raramente provêm uma vantagem competitiva sustentável” (p. 60). Esta só se mantém por meio de habilidades humanas selecionadas, capacitações logísticas, base de conhecimento e outras forças de serviço que os competidores não conseguem copiar e que levam a maior valor ao cliente. Não é por outro motivo que Normann e Ramirez (1993) disseram que a criação de valor advém da "co-produção com fornecedores, parceiros do negócios, aliados e clientes” (p. 65-66). Também é significativo que Evans e Wurster (1997) tenham dito que

A cadeia de valor também inclui toda a informação que flui dentro de uma empresa e entre uma companhia e seus fornecedores, seus distribuidores, $e$ seus clientes existentes ou potenciais. Os relacionamentos com os fornecedores, a identidade da marca, a coordenação do processo, a fidelização do cliente, a lealdade do empregado e os custos de mudança, todos dependem de vários tipos de informação. (p. 72)

5. Todas as economias são economias de serviços: o argumento de Vargo e Lusch (2004) é de que, tanto na classificação da atividade econômica quanto da era econômica, o denominador comum é o refinamento crescente e a troca de conhecimentos e de capacidades. Assim, tem havido crescente separação das atividades econômicas via especialização, salientando o papel dos serviços nelas aplicadas conforme estes se tornam mais visíveis na economia.

$6^{\text {a }}$. O cliente é sempre um co-produtor: bens são instrumentos que provêm serviços para e em conjunção com o cliente. No entanto, para estes serviços serem entregues, o cliente deve ainda aprender a usá-los, mantê-los, consertá-los, e adaptá-los às suas necessidades específicas e comportamento. Ou seja, ao usar um produto, o cliente está dando continuidade ao marketing, ao consumo, e aos processos de criação de valor e de entrega. Não é por outro motivo que Normann e Ramirez (1993) colocam que “...a chave para criar valor é co-produzir ofertas que mobilizem os clientes” (p. 69). Da mesma forma, Prahalad e Ramaswamy (2000) indicam que o mercado tornou-se o locus para o envolvimento do cliente proativo, e estimulam a co-optação do envolvimento do cliente no processo de criação de valor. Conforme muito bem colocam Vargo e Lusch, “... o cliente se torna um co-produtor mais do que um alvo, e pode ser envolvido na cadeia inteira de valor e de serviço ao agir sobre os recursos transformadores”. (p. 11) 
$7^{\mathrm{a}}$. A empresa pode somente lançar propostas de valor: esta premissa remete ao princípio de que, conforme Gummesson (1995),

[...] se o cliente é o ponto focal do marketing, a criação de valor só é possível quando um bem ou serviço é consumido. Um bem não vendido não possui valor, e um provedor de serviços sem clientes nada pode produzir. (p. 247)

8. Uma visão centrada no serviço é orientada para o cliente e é relacional: Davis e Manrodt (1966) salientam que, na visão centrada no serviço, a empresa ou o provedor de serviço devem reconhecer o problema do cliente, desenvolver uma solução customizada e entregá-la ao cliente. Ou seja, o que vale é não só fazer para o cliente, mas em uníssono com ele, num modelo de inseparabilidade entre aquele que oferece e aquele que consome.

\section{A teoria da cocriação de valor}

Ramirez (1999) introduziu a idéia de co-produção de valor em oposição à idéia tradicional de criação de valor industrial, indicando que uma das diferenças mais relevantes entre estas duas escolas de pensamento provém do papel do cliente. Na criação de valor industrial, os clientes eram vistos como "[...] destruidores do valor que os produtores lhes criaram [...]” (p. 51). Por esta tradicional visão centrada na empresa, no momento da interface desta com seus clientes o produto ou serviço seria simplesmente entregue a estes últimos, deste intercâmbio extraindo o fornecedor o máximo valor econômico que repusesse seus custos de produção e lhe fornecesse a margem de lucro desejada.

Já na visão alternativa de cocriação de valor, os clientes ativamente co-criam e recriam valor tanto com seus fornecedores como com seus próprios clientes. Assim, o princípio básico de integrar produtores e clientes no processo de criação de valor aplicado ao bem ou ao serviço intercambiado entre as partes descartaria, definitivamente, o paradigma anteriormente seguido de que a primazia por esta criação de valor seria exercida, de forma solitária, pelo produtor. Borys e Jemison (1989) definem o conceito de cocriação de valor de forma muito simples: trata-se de um processo pelo qual os recursos de duas empresas se combinam para se alcançar algo que uma das partes não alcançaria sozinha.

Mesmo saudada pela comunidade acadêmica, em seu formato original, como uma construção de elevado significado estratégico, a teoria da cocriação de valor não tem estado isenta de sofrer refinamentos conforme torna-se mais divulgada e estudada. Não se trata de questioná-la, mas sim de verificar-lhe particularidades que aumentem sua instrumentalidade na criação e manutenção das parcerias entre players no mercado industrial.

Passando-se à visão de Prahalad e Ramaswamy (2004) para a teoria da cocriação de valor, eles pregam que vem sendo observado um paradoxo no mundo corporativo no século atual: cada vez mais escolhas são disponibilizadas aos consumidores sem que os ofertantes lhes consigam assegurar a obtenção de satisfação.

Sua análise parte do resgate dos conceitos aplicados na pesquisa sobre estratégias empresariais ao final do século XX e início do século XXI, baseados na premissa de que as empresas "antigas" e consolidadas (chamadas de "tipo A") não desapareceriam no futuro, assim como as novas e exuberantes empresas "ponto com” (as "tipo B") não necessariamente sobreviveriam. O que aconteceria seria o aparecimento de um novo tipo de empresas (as "tipo C”) a partir da fusão e evolução das empresas A e B.

Examinando mais a fundo este fenômeno previsto, os autores verificaram que o cliente poderia participar ativamente no processo pelo qual todas estas empresas geram valor - ou seja, o cliente e a empresa estariam intimamente envolvidos na criação conjunta de valor que é diferenciado para o cliente e sustentável para a firma. 
Nesta nova visão conceitual, estaria sendo questionado o universo convencional das empresas dos tipos A e B, no qual quase todo o trabalho estava centrado nelas - daí a categorização tradicional dos negócios em business-to-business (B2B) e business-toconsumer (B2C), ambos colocando o negócio (business) em primeiro ligar, numa visão da economia centrada na empresa, onde esta cria e oferece valor aos clientes.

Nesta linha de raciocínio, os autores propuseram um modelo de atividade econômica consumer-to-business-to-consumer (C2B2C). Ele desafia as noções tradicionais de valor e de sua criação, assim como os dois princípios fundamentais de nosso sistema industrial, conforme sugere que: 1) os esforços conjuntos do cliente e da empresa - por meio da rede de relacionamentos das empresas e das comunidades dos clientes - sejam capazes de cocriarem valor por meio de experiências personalizadas que são específicas para cada cliente em especial; 2) estariam em cheque os princípios do valor em si, do processo de criação de valor, e da natureza do relacionamento entre a empresa e o cliente.

Neste novo paradigma, a empresa e o cliente criariam valor conjuntamente nos chamados "pontos de interação", momentos e locais onde a experiência de cocriação ocorre, com os clientes exercendo suas escolhas e o valor sendo criando em conjunto. Ou seja, é eliminado o conceito tradicional de que as empresas pensam e agem unilateralmente. No caso, o papel do cliente passa a ser fundamental nesta criação de valor, conforme deixa de ser um ente isolado e passivo para tornar-se conectado e ativo, características que trazem impactos diversos.

Com acesso à informação - por exemplo, via Internet - os clientes passam a ter uma visão globalizada dos bens e serviços, e não mais aquela informação tradicional restrita a limites geográficos. Com isto, os clientes expandem seus padrões de preferência de consumo para além das fronteiras tradicionais, passando a desafiar as tradições das indústrias mais variadas acostumadas a restringirem suas informações. Por exemplo, de simples pacientes, aqueles que necessitam de ajuda médica passam a agir como clientes ativos dos cuidados médicos, procurando, na Internet, informações sobre os tratamentos, pesquisando sobre a qualidade dos hospitais e compartilhando suas experiências com outras pessoas.

O recurso da Internet, aliado aos fortes avanços na comunicação de voz e de dados via telefonia celular, por exemplo - ao garantir o crescimento da comunicação entre os clientes também tem dado margem ao aparecimento das comunidades temáticas de clientes. Ali eles compartilham idéias sem a interferência de barreiras sociais ou geográficas, e - o que é mais importante - de forma independente das empresas que desejam servi-los. Com isto, o padrão tradicional das comunicações de marketing “de cima para baixo” (ou seja, da empresa para o público) passa a inverter-se, conforme a rede de comunicação dos clientes consegue ser muito eficiente na divulgação dos custos e benefícios associados ao consumo de um bem ou serviço.

Por isto mesmo, a Internet fez surgir aquilo que Prahalad e Ramaswamy (2004) chamam de "ativismo dos clientes", que passam a dispor de poderosa arma para consolidarem suas posições no que se refere aos mais variados tipos de consumo. Como exemplo, têm-se os blogs, que, por meio da visão de um indivíduo sobre determinado assunto, expressado via textos, imagens e links na web, estimulam o debate público e a manifestação de opiniões. Outro exemplo são os sites criados especificamente para registrar as más experiências dos clientes.

Por meio destas colocações, Prahalad e Ramaswamy (2004) demonstram que tem havido uma forte mudança no papel dos clientes, e, por consequência, as empresas e provedores de serviços 
[...] não mais podem agir de forma autônoma, desenhando produtos, desenvolvendo processos de produção, construindo mensagens de marketing e controlando canais de vendas com pouca ou nenhuma interferência dos clientes. (p. 4-5)

Como visto, o novo paradigma de criação de valor e de estratégia empresarial proposto por Prahalad e Ramaswamy (2004) baseia-se em um conceito fundamental: a criação de valor deixa de ser um processo unilateral para tornar-se bilateral, já que o cliente passa a nele desempenhar papel determinante. Por outro lado, os autores também colocam que esta nova visão levanta questões importantes para os provedores de bens e de serviços, assim como propõem formas de estes últimos lidarem com esta nova realidade.

\subsection{As especificidades dos relacionamentos para o sucesso da cocriação de valor}

Conforme colocado, à medida que a criação de valor passa a ser visto como possível a partir da interface entre as partes envolvidas na compra e na venda de um bem ou serviço, o relacionamento entre estas passa a envolver mais do que apenas aspectos monetários diretos. Esta nova configuração implica que, no limite, elas passem a agir em redes de relacionamentos, conforme as tradicionais perspectivas do comprador e do vendedor passam a ser uma só - a perspectiva do comprador-vendedor - que parte do princípio de que haja duas partes envolvidas ativamente em relacionamento que visa à criação de valor (FORSSTROM, 2003).

Estes relacionamentos comprador-vendedor são ativos importantes em uma empresa, devendo ser administrados de forma continuada e cuidadosa por ambas as partes, frequentemente por um longo período. Para Ford et al. (1998), o relacionamento, mais do que apenas encomendas, vendas, projetos, produtos e mercados vistos de uma ótica individual, é a melhor perspectiva para se analisar um negócio, ou para se tomarem decisões, ou para se avaliar o valor que está sendo criado.

Por isto mesmo, estes autores entendem que cada relacionamento deve ser examinado pelas óticas tanto do comprador quanto do vendedor: quais os componentes principais do valor para o comprador? Qual a opinião a respeito por parte do vendedor? Como ambos percebem o valor advindo da relação?

\section{As modelagens de cocriação de valor de Payne, Storbacka e Frow (2008) e de Möller, Rajala e Westerlund (2007)}

A modelagem de cocriação de valor de Payne, Storbacka e Frow (2008) se propõe a informar às organizações as formas como este procedimento deveria ser desenvolvido.

Sua modelagem se baseia, fundamentalmente, na ênfase dos processos, remetendo a Vargo e Lusch (2004) quando estes enfatizam que marketing deve ser visto como um conjunto de processos e de recursos com o quais a empresa busca criar propostas de valor. Neste sentido, processos incluem procedimentos, tarefas, mecanismos, atividades e interações que suportam a cocriação de valor. E esta visão de processos

[...] acentua a necessidade de se ver o relacionamento entre o provedor e o cliente como um grupo de experiências e de atividades longitudinais, dinâmicas e interativas, desempenhadas pelo provedor e pelo consumidor, dentro de um contexto, usando instrumentos e práticas que são parcialmente francos e deliberados, e parcialmente baseados na rotina $e$ no comportamento inconsciente. (PAYNE ET AL, 2008, p. 85)

Com base nestes fundamentos, Payne, Storbacka e Frow definiram que seu modelo (ver Figura 1) consistiria em três componentes principais: 
$1^{\circ}$. Processos de criação de valor do cliente: processos, recursos e práticas usados pelos clientes para desempenharem suas atividades

$2^{\circ}$. Processos de criação de valor dos ofertantes: processos, recursos e práticas usados pelos fornecedores para administrarem seu negócio e seus relacionamentos com os clientes e com outros stakeholders relevantes

$3^{\circ}$. Processos de encontro: processos e práticas da interação e do intercâmbio que ocorrem dentro do relacionamento cliente-ofertante, e que precisam ser administrados para o surgimento de oportunidades bem sucedidas de cocriação de valor.

Figura 1 - Modelo Conceitual de Cocriação de Valor

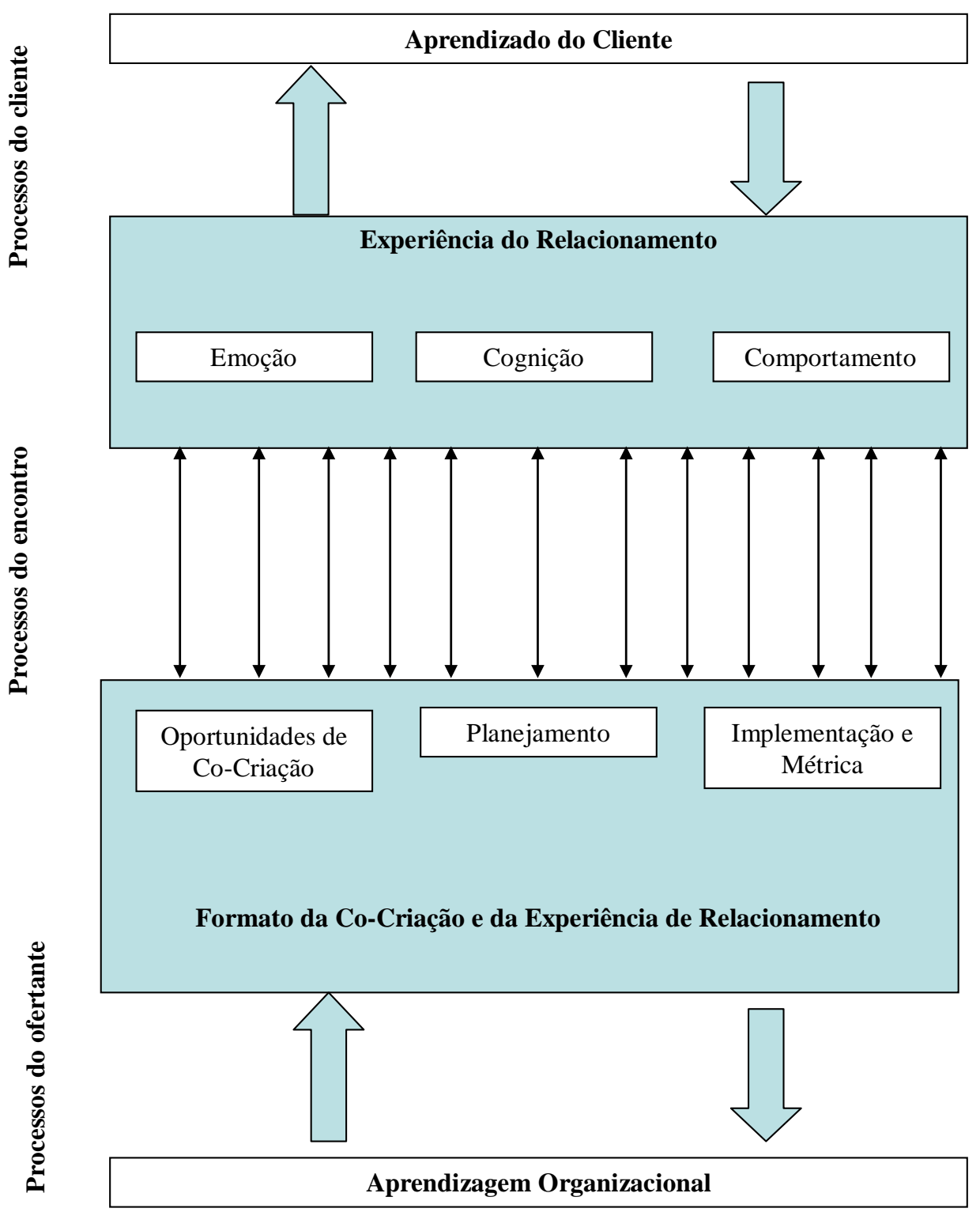

Fonte: Payne, Storbacka e Frow (2008) 
Concentrando-se no primeiro ponto - tendo em vista nosso objetivo primário de ligar a cocriação de valor à fidelização dos clientes - temos que ali reside a grande diferença entre a lógica serviço-dominante e a tradicional lógica bens-dominante, já que a primeira embute as experiências que o cliente experimenta ao longo do tempo. Não mais é importante a criação de produtos em si, mas sim o entendimento de seu potencial em cocriar experiências relevantes.

Para avaliar melhor a experiência relacional que se dá após o processo do encontro, Payne, Storbacka e Frow notam que ela pode ser considerada de duas perspectivas, no que tange à corrente de pesquisa do consumidor: pela abordagem do processamento da informação, e pela abordagem experimental.

No primeiro caso, trata-se, conforme colocou Oliver (1999), de ver os clientes envolvidos no processo cognitivo de julgamento com base na importância que atribuem a experiências passadas, presentes ou futuras. Ou seja, do cliente espera-se que tenha a capacidade de avaliar os benefícios e os sacrifícios de um produto ou de um relacionamento. Desta forma, ele desenvolve atitudes em consonância com suas metas: ele busca informação, ele avalia as opções disponíveis e ele decide se deve ou não adquirir um bem ou um serviço.

A abordagem experimental, por sua vez, alargou profundamente o conceito do comportamento do cliente, ao enfatizar os aspectos do consumo que remetem às emoções, ao contexto, ao simbolismo e aos aspectos não utilitários, conforme Arnould e Thompson (2005). Neste sentido, o valor residiria não no objeto de consumo, mas sim na experiência do consumo, incluindo as fantasias e os sentimentos, com o cliente se transformando como alguém que sente e que pensa.

Ainda no que tange aos processos do cliente em seu modelo, Payne, Storbacka e Frow alertam que, embora tenham ressaltado os papéis da emoção, da cognição e do comportamento do cliente como fundamentais para a experiência do relacionamento, eles têm que ser vistos em um contexto muito mais amplo do que aquele verificado na teoria comportamental tradicional no marketing. Conforme Holbrook e Hirschman (1982), a cognição deve ser entendida pelo lado do processamento de informações focalizado em processos subconscientes e pessoais. Ou seja, emoções e sentimentos teriam um sentido muito amplo, englobando estados de espírito e características de personalidade ligadas à forma de sentir as emoções. Consequentemente, a análise do comportamento deveria ir além dos processos de escolha que levam às decisões de consumo, passando a incluir experiências que os clientes obtêm a partir do uso de um produto ou de um serviço.

Em que pese a lógica deste raciocínio, há vozes acadêmicas que pregam que, mais do que apenas garantir-se que a cocriação de valor possa se concretizar - via, por exemplo, esta modelagem de Payne, Storbacka e Frow - há algo mais a ser pesquisado interiormente a esta criação em si.

Este é o ponto de vista de Möller, Rajala e Westerlund (2007), que, mais do que interessados no fenômeno da cocriação do valor em si, mostraram-se preocupados com as especificidades apresentadas por esta cocriação para qualquer das duas partes - ofertante ou cliente. Para estes autores, muito embora a proposta da cocriação de valor seja a de estimular uma mudança positiva no serviço, o efeito desta mudança no serviço percebido por um dos atores, ocorrido por meio daquela pretensa adição de valor, pode assumir aspecto não obrigatoriamente positivo do seu ponto de vista.

O que estes pesquisadores querem dizer é que, se é verdade que o modelo tradicional de negócios se fundamenta na proposta de criação de valor, ele também sofre as restrições impostas pela posição de cada ator e pelo papel destes no sistema de valor. Em outras palavras, àquele modelo faltaria uma atenção quanto aos modelos individuais de cada player 
no que tange às competências, às vantagens competitivas e à lucratividade, na medida em que superenfatiza os interesses individuais do produtor ou do cliente.

Vem daí a conclusão de que as mudanças aplicadas com vistas à inovação dos serviços serão positivas para as perspectivas tanto do cliente quanto do produtor apenas se houver uma congruência estratégica entre ambos. Ou seja, se ambos tiverem estratégias de criação de valor suficientemente relacionadas.

Para estudar estas mudanças e construírem sua modelagem analítica para o desenvolvimento dos serviços, Möller, Rajala e Westerlund propuseram uma tipologia para as alterações/inovações aplicadas aos serviços, que foram por eles classificadas como "incrementais" e "radicais".

A mudança incremental enquadra-se em uma visão de menor prazo, tendo a ver apenas com melhorias aplicadas no formato e/ou na forma de implementação já presentes do serviço. No caso, pode variar desde aperfeiçoamentos muito simples e autônomos até melhorias sistêmicas complexas que requeiram a colaboração de vários atores do sistema de valor.

Já as mudanças radicais, como o próprio nome diz, revelam-se extremas: serviços completamente novos delas resultam, implicando a quebra de paradigmas tradicionais de criação de valor. Vale notar dois aspectos muito interessantes que são ressaltados por Möller, Rajala e Westerlund neste caso. O primeiro é que, embora estas mudanças requeiram ambiente empresarial propício às inovações, não há clareza quanto à origem destas mudanças residir em estratégias conscientes das empresas. O segundo é que este valor destes serviços completamente novos pode ser criado por parceiros ainda desconhecidos à época do surgimento da inovação.

A partir deste enfoque, os autores definiram seu modelo de criação de valor, o Service Innovation Mode Framework ${ }^{4}$, apoiado na construção de matriz 3 X 3 onde se combinam as estratégias tanto do cliente quanto do ofertante (ver Figura 2). Estas estratégias foram distribuídas em três níveis: para serviços consolidados, para inovações incrementais em serviços, e para inovações radicais em serviços. Suas especificidades são as seguintes:

1) Serviços consolidados: neste caso, trata-se de serviços que são transacionados em mercados onde impera forte competição, o que obriga os ofertantes a priorizarem a eficiência operacional. Este seria o caso da Dell,

[...] cuja posição de destaque no mercado de computadores foi alcançada por meio da oferta de produtos e de serviços modulares padronizados em vendas diretas aos clientes, numa proposta de valor homogêneo para a clientela global. (MÖLLER;RAJALA; WESTERLUND, 2007, p. 6).

Figura 2 - Formas básicas de interação para a cocriação de valor

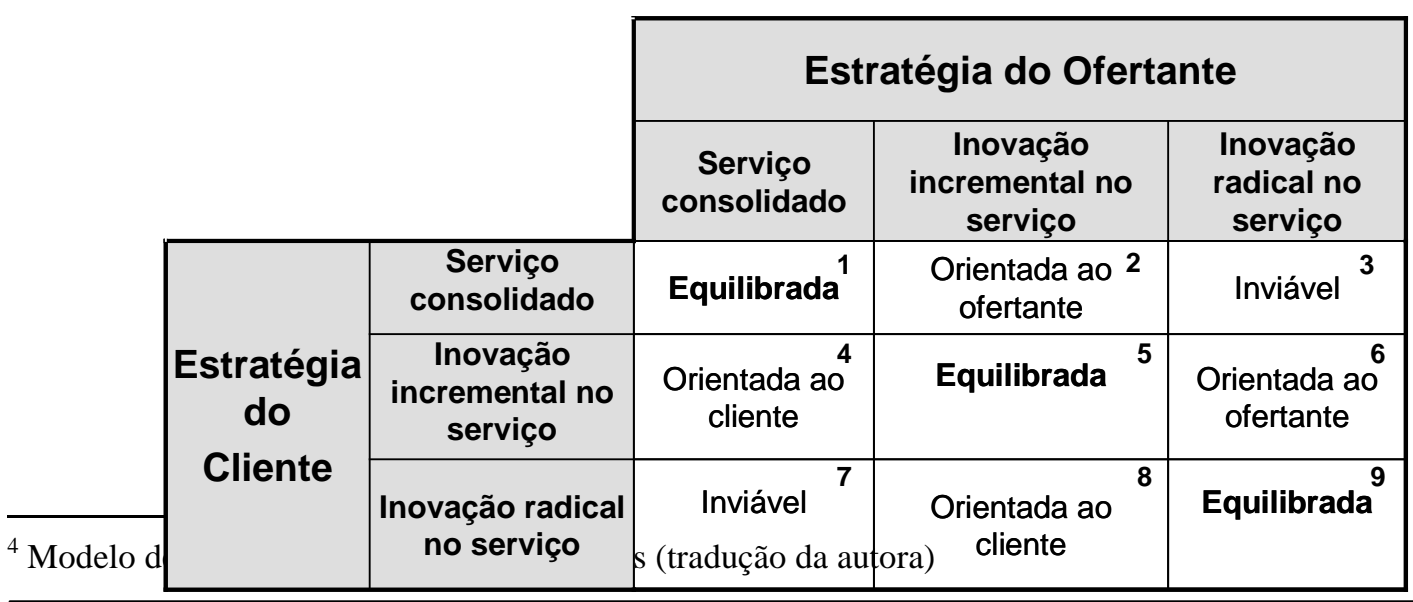

Revista de Negócios, ISSN 1980-4431, Blumenau, v15, n.29, p.57 - 76, Janeiro/Março 2010. 
Fonte: Möller, Rajala; Westerlund (2007)

2) Inovações incrementais em serviços, objetivando adicionar-lhes valor: a idéia-chave é que, por meio de investimentos e adaptações mútuos, o ofertante de um serviço e seu cliente podem produzir soluções mais eficientes do que as já existentes. Este seria o caso do Google: recusando-se a aceitar as limitações dos conceitos já existentes e codesenvolvendo serviços com seus clientes - tarefa que os criadores do Google continuam a executar, em linha com sua filosofia de continuamente explorar formas de tecnologia que possam melhorar seu desempenho operacional - seus criadores inventaram uma nova forma de organizar, muito velozmente, a quase infinita quantidade de informações que permeia a internet.

3) Inovações radicais em serviços, transformando-os em algo totalmente inédito. É o caso do MySQL, sistema de gerenciamento de banco de dados de código aberto que conta com mais de 10 milhões de instalações pelo mundo - tais como entre websites, data warehouses e aplicações comerciais - e cuja missão é criar um banco de dados que contribua para aplicações de missão crítica, com altos volumes. Sua idéia inovadora é de que o código-fonte do software esteja irrestritamente disponível e acessível a todos para uso e/ou para modificações, desde que todos os trabalhos daí advindos sejam repassados aos desenvolvedores do MySQL. Portanto, este princípio de licenciamento protege e estimula o co-desenvolvimento de software e a cocriação de conhecimento entre inovadores, desenvolvedores e clientes. Com isto, é gerado sistema ilimitado de criação de valor onde interage um número irrestrito de atores - muitos cuja identidade o MySQL nem chega a conhecer - com possibilidades ilimitadas de trazerem novos avanços a esta inovação. Ou seja, trata-se de estratégia de criação de valor voltada para o futuro, apoiada em mudanças sistêmicas radicais nos conceitos existentes de valor.

O que salta aos olhos é que o foco do modelo são as formas básicas de interação cliente-ofertante para a cocriação de valor, nas quais ambos os players podem se posicionar em qualquer uma das três estratégias: de serviço consolidado, de inovações incrementais e de inovações radicais. Sua matriz representativa mostra que as relações cliente-ofertante só gerarão inovações de serviços bem sucedidas conforme as organizações consigam reconhecer as estratégias de criação de valor de ambas as partes. Por isto, não haveria nenhuma possibilidade de a cocriação de valor ocorrer quando houver extrema discrepância entre as estratégias do cliente e do fornecedor (células 3 e 7 da matriz). Por outro lado, esta possibilidade ocorreria de três formas, sempre que houvesse interação cliente/fornecedor para a cocriação de valor:

1) orientada ao ofertante (células 2 e 6): a cocriação de valor surgiria a partir da tendência de os ofertantes de serviços visarem-na por meio de relacionamentos distantes e meramente transacionais com os clientes, conforme priorizam sua eficiência operacional. Assim, haveria a aplicação de inovações (incrementais ou radicais) no serviço por determinação da estratégia do ofertante, indicando que estas iniciativas são bem sucedidas caso se apliquem sobre um serviço estrategicamente visto pelo cliente como consolidado (no caso da inovação incremental) ou sobre um serviço estrategicamente visto pelo cliente em um contexto que já acomode inovações incrementais (no caso da inovação radical). Para este último caso (situado na célula 6), o exemplo de Möller, Rajala e Westerlund é o do iTunes da Apple. Trata-se de uma mídia digital que serve para tocar e organizar música digital e 
arquivos de vídeo, além de ser uma interface para administrar o conteúdo dos populares iPods da Apple. Ou seja, a empresa conseguiu introduzir uma inovação radical em seu iPod, serviço este que, já completamente absorvido pelos clientes, acomoda esta inovação, vista por eles como incremental. Assim, neste formato de cocriação de valor, usualmente a tecnologia é utilizada para o desenvolvimento de serviços inovadores, a serem direcionados a clientes prospectivos. Vale notar, porém, que esta inovação implica desafios, já que forçála a clientes que não estejam desejosos de compactuarem com as prioridades da organização pode ensejar impactos negativos tanto sociais quanto econômicos, que terminariam por causar desgaste na relação entre as partes.

2) orientada ao cliente (células 4 e 8): trata-se de contexto desequilibrado para a inovação do serviço, com as necessidades e expectativas dos clientes quanto a esta inovação excedendo o desejo dos ofertantes em se esforçarem para atendê-los. Neste contexto, as propostas de valor são dirigidas apenas às necessidades explícitas de clientes conhecidos. Assim, a organização visa, por meio de uma inovação centrada no cliente, a atender, da melhor forma possível, a necessidades já existentes, utilizando soluções bem definidas e orientadas para o mercado. Em nível relacional, esta abordagem prejudica a postura colaborativa conforme prioriza as necessidades imediatas dos clientes. Isto reduz a própria capacidade de reprodução do serviço, além de poder afetar a fidelização dos clientes, conforme estes se frustrem com a relutância dos ofertantes em investirem na inovação orientada ao cliente. Para a célula 4 (melhorias incrementais para o cliente aplicadas sobre um serviço consolidado) seria adequado, por exemplo, o caso da Dell, que atendeu à demanda de seus clientes para não terem que adquirir seus computadores com softwares pré-instalados - atendimento este provavelmente realizado a contragosto pela empresa, já que esta pré-instalação originalmente lhe gerava uma receita extra. O que deve ser ressaltado aqui é que, se o ofertante não dispuser das necessárias competências e de boa vontade para desenvolver as competências requeridas por seus clientes, estes poderão simplesmente procurar novos parceiros. Por outro lado, os ofertantes devem possuir a sensibilidade necessária para não exagerarem seu foco nas necessidades imediatas dos clientes: isto pode criar um desvio na atividade de inovação colaborativa, pernicioso ao bom desempenho empresarial conforme limita seu potencial futuro ao reduzir o alcance do serviço sobre outros clientes.

3) aquela advinda de inovação ditada por uma postura colaborativa ofertante-cliente (células 1, 5 e 9): aqui residiriam os modelos de negócios mais bem sucedidos, já que ambos os players "[...] entenderiam a lógica de criação de valor um do outro, assim como as metas e atividades que tornam ambos os lados mais competitivos.” (MÖLLER, RAJALA E WESTERLUND, 2007, p. 4).

Neste sentido, a cocriação de valor se situaria em um ambiente de superioridade competitiva mútua, concretizada em modelos de negócios com foco concentrado nos serviços, priorizando a complexidade relacional, as prioridades operacionais e as exigências cognitivas. Em outras palavras, ambas as partes perseguem estratégia similar, seja com foco em serviços consolidados, seja em inovações incrementais ou radicais nos serviços. Assim, os benefícios nos serviços ficam muito claros na proposta de valor, e os clientes apresentam as necessárias competências para consumi-los ${ }^{5}$. Um dos exemplos dados por Möller, Rajala e Westerlund para este caso é o do Skype, serviço gratuito de comunicação ilimitada de voz e de imagem pela internet, e que se encaixa na célula 9 do modelo. Esta inovação radical no serviço de internet traduz-se em uma típica situação de ganha-ganha na cocriação de um serviço: trata-se

\footnotetext{
${ }^{5}$ Isto não impede, porém, que os relacionamentos entre as partes passem a tornar-se altamente complexos e às vezes contraditórios, significando desafios à criação coletiva de valor.
} 
de um conceito de serviço que promove uma aproximação de pessoas que possuem a expertise e o conhecimento para propagandeá-lo a terceiros.

Portanto, o que se observa nesta modelagem é que Möller, Rajala e Westerlund ressaltam um aspecto da estratégia e cocriação de valor que, embora muito relevante, tem sido omitido por muitos dos pesquisadores que estudam este tema, e que caracteriza a grande contribuição do modelo à teoria: a incongruência que pode existir nos focos dos clientes e dos ofertantes. Assim, conforme estes últimos entendem a cocriação de valor como uma variável dependente do seu modelo organizacional, eles são levados a criar relacionamentos mais - ou menos - próximos de seus clientes. E, vez que este é um fato dado - tendo em vista que a vocação da empresa ofertante pode ser entendida como imutável por seus dirigentes - os autores concluem que

Para desenvolverem inovações de serviços bem sucedidas por meio de relacionamentos cliente-ofertante, as empresas devem primeiramente reconhecer as respectivas estratégias de criação de valor. (p. 8)

É importante ressaltar que, como o modelo de Möller, Rajala e Westerlund frisa que a interação mais eficiente para a cocriação de valor é aquela em que as estratégias dos clientes e dos ofertantes convergem entre si, um desafio que se coloca para estes últimos é conseguirem que, em um contexto de inovação, os clientes retenham o valor trazido por esta última. Em outras palavras, se o cliente não conseguir conciliar uma oferta de valor complexa com as competências de que já dispõe, ele não compreenderá nem usufruirá deste valor. Com isto, ficará mais vulnerável a eventuais abordagens da concorrência.

Traçando um paralelo entre esta linha de raciocínio e a teoria da fidelização de Oliver (1999), temos que, para garantir a lealdade dos clientes, não bastaria somente que estes se vissem como co-participantes na criação do valor, mas que se sentissem verdadeiramente envolvidos com a organização a ponto de esta significar-lhes mais do que apenas a provedora de um serviço qualquer. Sendo assim, seria da maior relevância que as organizações tivessem muita atenção ao identificarem em qual célula do modelo de Möller, Rajala e Westerlund se encontram, de forma a identificarem com muita clareza em qual linha estratégica se situam e agirem em consonância com esta identificação.

Por exemplo, caso as estratégias desta cocriação se localizem nas células 4 e 8 do modelo de Möller, Rajala e Westerlund, o entendimento (incorreto) dos clientes como meros coadjuvantes poderia se verificar caso os ofertantes, conforme já apontado, não possuíssem a sensibilidade necessária para não exagerarem seu foco nas necessidades imediatas dos clientes, criando um desvio na atividade de inovação colaborativa.

Já no que tange às estratégias localizadas nas células 2 e 6 do modelo, seria necessário que os clientes estivessem capacitados para usufruírem dos benefícios extras trazidos pelo aprimoramento do serviço. Para resolver esta questão, dentre os caminhos disponíveis pode-se imaginar que um dos mais relevantes seria promover o aprendizado dos clientes. Para tanto, os ofertantes teriam que lidar com diversos desafios, dentre os quais se destaca aquele referido à cultura da sua própria organização. Ou seja, esta teria que aprender a repensar o papel dos seus clientes, que teriam que passar a ser vistos como co-participantes e não mais como meros receptores.

Esta capacidade de entendimento nas empresas passaria pelo desenvolvimento da sensibilidade necessária para saberem o que compartilhar, e o que não compartilhar, com seus clientes. Isto porque o processo de cocriação não implica simplesmente colocar o cliente a par de todo o processo de produção e de comercialização do serviço. Conforme ressaltam Payne, Storbacka e Frow (2007), os processos de encontro entre o cliente e a organização geram, no cliente, a experiência do relacionamento, alimentando seu próprio aprendizado. Neste sentido, 
seria necessário que as organizações adequassem seu marketing de relacionamento e seus sistemas automatizados de marketing, caso o potencial destes fosse insuficiente para a concretização deste aprendizado. Em outras palavras, as organizações deveriam despender mais tempo e mais recursos para aumentarem a inteligência de suas ferramentas de marketing de relacionamento, de forma a utilizá-las como meios não só de divulgação do serviço mas também de aprendizagem do cliente. A título de ilustração, pode-se imaginar que, neste particular, longo caminho têm a trilhar as provedoras de serviços que muito se apóiam em contact centers para interfacearem com sua clientela.

\section{Introdução ao segmento citrícola brasileiro}

O Brasil é o maior produtor e exportador mundial de laranja e do suco desta fruta. Concentrado no estado de São Paulo, o agronegócio citrícola brasileiro, composto pelos pomares basicamente de laranja e pelo parque industrial de empresas que transformam esta fruta em suco, na verdade abrange muito mais do que apenas estes dois players. Isto porque, numa visão mais macro, ele se inicia na indústria de insumos à lavoura e passa, sucessivamente, pelas atividades da lavoura da laranja, de seu transporte às empresas produtoras do suco, da transformação da fruta em suco, da sua distribuição atacadista e, finalmente, da sua distribuição tanto no mercado brasileiro quanto no exterior (ver Figura 3). Numa visão ainda mais estendida, podem-se considerar também os fabricantes de suco que também atuam na Flórida, onde já são responsáveis por 1/3 de todo o processamento local desta fruta.

No agronegócio brasileiro da citricultura, as plantações comerciais de laranja que não pertencem às empresas produtoras de suco (ou seja, de produtores ditos independentes) são destinadas fundamentalmente a abastecer estas últimas. Em outras palavras, há uma dependência mútua entre estes players, uma vez que sem laranja não há suco, e que o mercado interno de fruta in natura é capaz de absorver menos de $1 / 3$ da sua colheita comercial.

Figura 3 - Representação do Sistema Agroindustrial Citrícola Brasileiro e Valores Gerados por Alguns de Seus Players em 2003 


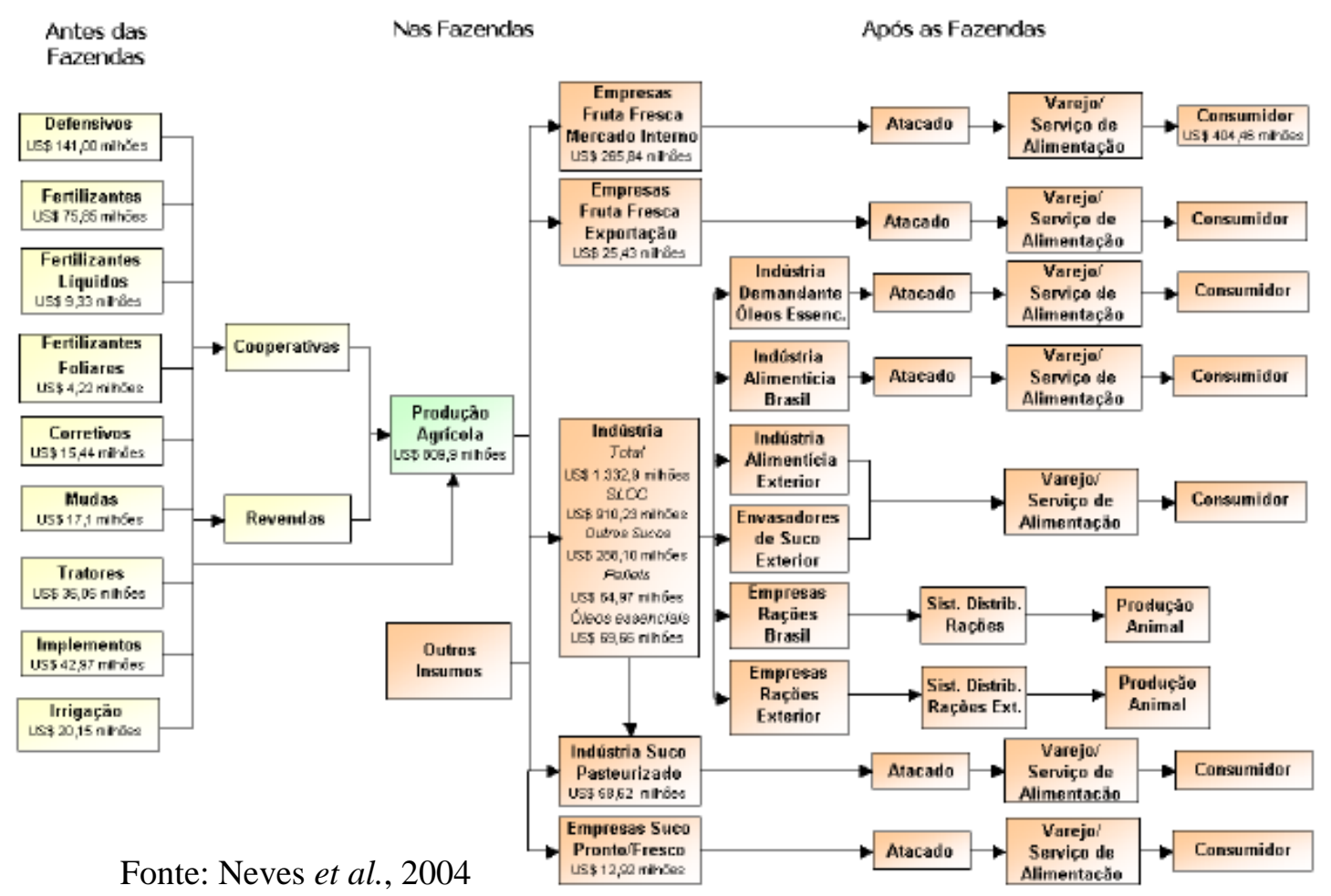

Neste ambiente de negócios, citricultores e empresas são clientes um do outro, coexistindo em ambiente de negócios pautado fundamentalmente pela demanda externa à bebida brasileira, iniciada na década de 1970 conforme as geadas que atingiram a região produtora de laranja na Flórida causaram o desabastecimento do mercado norte-americano, maior consumidor per capita de suco de laranja até hoje. Ou seja, aqui tem-se uma configuração business-to-business em que a cocriação de valor emergeria de forma natural, tendo em vista a complementaridade das funções exercidas por ambos os players.

Interessantemente, porém, esta dependência mútua não tem sido capaz de amenizar, ao longo de mais de 30 anos, as divergências de interesses de ambas as partes. No caso, os citricultores frequentemente entendem que a indústria se beneficia de movimentos altistas no mercado do suco sem lhes repassar o devido benefício aos preços do insumo laranja. De sua parte, as empresas de suco entendem que os citricultores se recusam a entender os princípios que norteiam suas inter-relações, adotando postura belicosa que não raro remete a ações levadas ao poder arbitral do Judiciário.

\section{Considerações finais}

Cocriar valor não é tarefa fácil. Requer muito mais do que a simples boa intenção das organizações, indo desde a detenção de ativos tangíveis - tais como ferramentas por meio das quais é possibilitada sua interação com os clientes - até exigências intangíveis que podem levar muito tempo para serem executadas - tais como a mudança na cultura organizacional.

Da parte dos clientes, também várias questões se colocam. Eles têm que ter a competência e a habilidade para interagirem com os ofertantes por meio dos instrumentos que estes lhes disponibilizam. Afinal, de que adiantará a organização disponibilizar um weblog se a maior parte dos seus clientes não possui acesso à internet?

Porém, em que pesem estas dificuldades, a cocriação de valor é conceito definitivamente instalado no contexto acadêmico tanto do marketing quanto da estratégia empresarial. O que não impede que muitas questões por ele trazidas ainda requeiram 
discussões muito mais aprofundadas, com vistas à construção de conhecimento necessário a seu maior entendimento.

Dentre estas questões destaca-se a grande importância da cocriação de valor na teoria interorganizacional. Além de suas variáveis tradicionais serem muito diversas daquelas existentes no ambiente de relacionamento do fornecedor de bens ou de serviços com o cliente pessoa física, o ambiente industrial encontra-se sob forte influência da visão relacional, com ênfase nas redes de relacionamento.

Isto implica uma visão muito especial da cocriação de valor, uma vez que a relação empresarial implica que esta cocriação se dê por meio da interdependência entre as atividades, englobando esta as conexões entre atores, atividades e recursos, aspectos específicos e muito complexos voltados para a manutenção das redes de relacionamento. De fato, a vasta literatura a respeito do fenômeno da criação de valor no ambiente empresarial - por exemplo, Lapierre (2000), Rint, Woodruf e Gatdial (1997), Johnson (1999) e Sharma e Sheth (1997) porquanto não esgote o assunto, fornece importante subsídio para este assunto.

Tendo isto em vista, e que a cadeia citrícola envolve um evidente encadeamento de atividades de agentes que se complementam uns aos outros, fica claro que é possível estudarse a cocriação de valor entre quaisquer dos elos que formam esta cadeia sob a ótica dos relacionamentos de redes de negócios. Assim, sugere-se utilizar o arcabouço teórico aqui apresentado para, em artigo futuro, avaliar-se a cocriação de valor dentro do sub-segmento da citricultura brasileira representado pelas relações entre dois players em especial: os produtores de laranja e as empresas processadoras de suco.

O interesse por esta investigação deriva de dois fenômenos. Um deles é o elevado valor que o agronegócio brasileiro citrícola representa para a economia do País: conforme a Associação Nacional dos Fabricantes de Sucos Cítricos (CitrusBR), mesmo com a queda da produção de laranja a receita brasileira com as exportações de suco deverá crescer $20 \%$ em 2010 relativamente a 2009, para aproximadamente US\$ 2 bilhões. Este valor revela-se ainda mais significativo se levar-se em conta que este produto consegue ser competitivo no mercado norte-americano, para aonde vão cerca de $20 \%$ das exportações brasileiras, apesar da barreira tarifária da ordem de US\$ 418 aplicada por tonelada do suco concentrado congelado ${ }^{6}$, além das tarifas antidumping específicas que têm vigorado desde 2005 para as empresas exportadoras em si, e que variam de 9,73\% até 60,29\%.

O outro fator são os conflitos que, historicamente, têm caracterizado as relações entre produtores de laranja e indústria transformadora do suco, tendo em vista que os primeiros frequentemente entendem que esta última se beneficia de movimentos altistas no mercado do suco sem lhes repassar o devido benefício aos preços do insumo laranja.

Assim, fundamenta-se a proposta de avaliar-se até que ponto a existência destes conflitos prejudica o processo de cocriação de valor, contribuindo para impedir uma ainda maior competitividade deste segmento no agronegócio brasileiro e para prejudicar o alcance de patamares ainda mais significativos do que os observados no resultado econômico desta atividade. Esta avaliação pretende-se objeto de artigo em continuação a este, conforme indicado anteriormente numa futura colaboração acadêmica à Agenda 2015.

\section{Referencial Bibliográfico}

ACHROL, R. S.; KOTLER, P. Marketing in the Network Economy. Journal of Marketing, 63 (Special Issue), 146-63, 1999

\footnotetext{
${ }^{6}$ Em maio de 2010, a tonelada do suco de laranja concentrado congelado na Bolsa de Nova York valia US\$ $2.720,00$.
} 
ALDERSON, W. Marketing Behavior and Executive Action: A Functionalist Approach to Marketing Theory. Homewood, IL: Richard D. Irwin, 1957

ANDERSON, J.C., JAIN, D.; CHINTAGUNTA, P. Customer value assessment in Business Markets: a state-of-practice study, Journal of Business-to-Business Marketing, vol. 1, n. 1, 3-29, 1993

ANDERSON, E.W.; SULLIVAN, M.W. The Antecedents and Consequences of Customer Satisfaction for Firms. Marketing Science, Vol. 12, No. 2, 125-143, 1993

ARNOULD, E. J.; THOMPSON, C. J. Consumer culture theory (CCT): Twenty years of research. Journal of Consumer Research, 31, 868-882, (March), 2005

BENDAPUDI, N.; LEONE, R.P. Psychological Implications of Customer Participation in CoProduction. Journal of Marketing, Jan. Vol. 67, 14-28, 2003

DAVIS, FRANK W.; MANRODT, K. B. Customer-Responsive Management: The Flexible Advantage. Cambridge, MA: Blackwell, 1996

DESARBO, W.S.; HUFF, L.; ROLANDELLI, M.M.; CHOI, J. On the measurement of Perceived Service Quality: A Conjoint Analysis Approach, in Service Quality: New Directions in Theory and Practice, Roland T. Rust and Richard L. Oliver, eds. Thousand Oaks, CA: Sage Publications, 201-22, 1994

EVANS, P. B.; WURSTER, T. S. Strategy and the New Economics of Information. Harvard Business Review, 75 (September-October), 71-82, 1997

FORD, D.; GADDE, L.; HAKANSSON, H.; LUNDGREN, A.; SNEHOTA, I.; TURNBULL, P.; WILSON, P. Managing Business Relationships. John Wiley; Sons Ltd., England, 1998

FORSSTROM, B. The conceptual exploration into "value-co-creation" in the context of industrial buyer-seller relationships. Work-in-Progress Paper, $19^{\text {th }}$ Annual IMP Conference, Switzerland, 2003

GUMMESSON, E. Relationship Marketing: Its Role in the Service Economy, in Understanding Services Management, William J. Glynn and James G. Barnes, eds. New York: John Wiley; Sons, 244-68, 1995

HAECKEL, S. H. Adaptive Enterprise: Creating and Leading Sense-and-Respond Organizations. Boston: Harvard School of Business, 1999

HOLBROOK, M. B.; HIRSCHMAN, E. C. The experiential aspects of consumption: Consumer fantasies, feelings, and fun. Journal of Consumer Research, 9, 132-140, (September), 1982

JOHNSON, Jean L. Strategic Integration in Industrial Distribution Channels: Managing Interfirm Relationship as a Strategic Asset, Joumal of the Academy of Marketing Science, 27 (Winter), 4-18, 1999

JUDD, R.C. The Case for Redefining Services, Journal of Marketing, 28, 58-59, 1964

LAPIERRE, J. Customer-Perceived Value in Industrial Contexts. Journal of Business and Industrial Marketing, 15 (2/3), 122-40, 2000

LEVITT, T. Marketing Myopia. Harvard Business Review, July/August, 3-13, 1960

MALTHUS, T. An Essay on the Principle of Population. London: Printed for J. Johnson, in St. Paul's Church-Yard. 
MÖLLER, K.; RAJALA, R.; WESTERLUND, M. Service Myopia? A New Recipe for ClientProvider Value Creation. The Berkeley-Tekes Service Innovation Conference in Berkeley, California, April 27-28, 2007

NEVES, M. F., LOPES, F.F., ROSSI, R.M.; MELO, P.A.O. Metodologias de análise de cadeias agroindustriais: aplicação para citros. http://www.favaneves.org/ index.php?registros=;cod_categoria=7;cod_secao=16;pag=2, 2004

NORMANN, R.; RAMIREZ, R. From Value Chain to Value Constellation: Designing Interactive Strategy. Harvard Business Review, 71 (July-August), 65-77, 1993

OLIVER, R. L. Satisfaction: A Behavioral Perspective on The Consumer. McGraw-Hill, 1997

OLIVER, R. L. Whence consumer loyalty? Journal of Marketing, Vol. 63 (Special Issue), 3344, 1999

PAYNE, A. F.; STORBACKA, K.; FROW, P. Managing the co-creation of value. Journal of the Academy Marketing Science, vol. 36, 83-96, 2008

PENROSE, E.T. The Theory of the Growth of the Firm. London: Basil Blackwell and Mott, 1959

PRAHALAD, V. K.; RAMASWAMY, V. Co-opting Customer Competence. Harvard Business Review, 78 (January-February), 79-87, 2000

PRAHALAD, V. K.; RAMASWAMY, V. The Value Creation Dilemma: New Building Blocks for Co-Creating Experiences. www. eccvenkat.com/The_Value_Creation _Dilemma_-_October_2001.pdf, 2001

PRAHALAD, V. K.; RAMASWAMY, V. The future of competition: Creating unique value with customers. Boston, MA: Harvard Business School Press, 2004

QUINN, J. B.; DOORLEY, T. L.; PAQUETTE, P. C. Beyond Products: Services-Based Strategy. Harvard Business Review, 68 (March-April), 58-66, 1990

RAMIREZ, R. Value co-production: intellectual origins and implications for practice and research. Strategic Management Journal, n. 20, 49-51, 1999

RAVALD, A.; GRÖNROOS, C. The value concept and relationship marketing. European Journal of Marketing, vol. 30, n. 2, 19-30, 1996

RINT, D.; WOODRUFF, R. B.; GATDIAL, S. F. Customer Value Change in Industrial Marketing Relationships: A Call for New Strategies and Research, Industrial Marketing Management, 26 (March), 163-75, 1997

SCHOUTEN, J. W.; MCALEXANDER, J.H. Subcultures of Consumption: an Ethnography of the New Bikers. Journal of Consumer Research, 22 (June), 43-61, 1985

SHARMA, A.; SHETH, J. Relationship Marketing: An Agenda for Inquiry, Industrial Marketing Management, 26 (2), 87-89, 1997

SHETH, J.; PARVATIYAR, A. "Relationship Marketing in Consumer Markets: Antecedents and Consequences," in Handbook of Relationship Marketing, Jagdish Sheth and A. Parvatiyar, eds. Thousand Oaks, CA: Sage Publications, 2000

SHETH, J.; SISODIA, R. S.; SHARMA, A. The Antecedents and Consequences of Customer-Centric Marketing. Journal of the Academy of Marketing Science, 28 (Winter), 55-66, 2000 
STORBACKA, K.,; LEHTINEN, J. R. Customer relationship management: Creating competitive advantage through win-win relationship strategies. Singapore: McGraw-Hill, 2001

VARGO, S. L.; LUSCH, R. F. Evolving to a new dominant logic for marketing. Journal of Marketing, 68, 1-17, 2004

WILSON, D.T. An integrated model of buyer-seller relationships. Journal of the Academy of Marketing Science, vol. 23, no.4, 335-345, 1995 